\title{
Grau de Concorrência e Poder de Mercado nas Exportações de Leite em Pó para o Brasil'
}

\author{
Lucas Campio Pinha², Marcelo José Braga ${ }^{3}$ e \\ Antônio Carvalho Campos ${ }^{4}$
}

Resumo: Há indícios de que Argentina e Uruguai atuem como oligopolistas e exerçam poder de mercado nas exportações de leite em pó para o Brasil. As firmas dos dois países supracitados exportam quase a totalidade destes derivados para o território brasileiro, ao passo que há uma regionalização do comércio internacional destes produtos, restringindo a concorrência com outros países. O objetivo central do presente trabalho é verificar o grau de concorrência nas exportações de leite em pó integral e desnatado para o Brasil pela existência do poder de mercado praticado pelos países exportadores. Para isto, utiliza-se o modelo de demanda residual, estimado por mínimo quadrado de dois estágios (MQ2E), seemingly unrelated regressions (SUR) e mínimo quadrado de três estágios (MQ3E). Os resultados indicam que o Uruguai atua como oligopolista e exerce poder de mercado em ambos os mercados, enquanto a Argentina, apenas no caso do leite em pó integral. Os resultados sugerem que o Brasil deve buscar meios de elevar a concorrência nas importações de leite em pó, já que, assim, os preços tenderiam a ser menores e os consumidores se beneficiariam neste aspecto.

Palavras-chaves: Concorrência; Poder de mercado; Leite em pó desnatado; Leite em pó integral; Exportação.

Abstract: There are indications that Argentina and Uruguay act as oligopolists and exercise market power in exports of milk powder to Brazil. These two countries export almost all of these by-products to Brazil, while there is a regionalization of international trade in these products, restricting the competition with other countries. The main objective of this paper is to verify the degree of competition in exports of whole milk powder and skimmed milk powder to Brazil by the existence of market power practiced by the exporting countries. For this purpose, the residual demand model was used, estimated by

1. Data de submissão: 10 de julho de 2014. Data de aceite: 23 de março de 2016.

2. Universidade Federal de Viçosa. Viçosa, Minas Gerais, Brasil. E-mail: lucascpinha@gmail.com

3. Universidade Federal de Viçosa. Viçosa, Minas Gerais, Brasil. E-mail: mjbraga@ufv.br

4. Universidade Federal de Viçosa. Viçosa, Minas Gerais, Brasil S. E-mail: accampos@ufv.br 
three different methods: two-stage least square, seemingly unrelated regressions and three-stage least squares. The results indicate that Uruguay acts as oligopolistic and exercises market power in both markets, whereas Argentina acts only in the case of whole milk powder. This suggests that Brazil should increase the competition in milk powder imports, since the prices would tend to be smaller and consumers would benefit in this aspect.

Key-words: Competition; Market power; Skimmed milk powder; Whole milk powder; Export.

DOI - http://dx.doi.org/10.1590/1234-56781806-94790540301

Classificação JEL: F12, F14, L13.

\section{Introdução}

Os derivados lácteos possuem algumas peculiaridades que os diferenciam de outros produtos agropecuários. Com poucas exceções, esses produtos são, em geral, perecíveis, o que dificulta as transações internacionais de longa distância e limita o crescimento do comércio internacional. Leite e Carvalho (2009) corroboram esta informação e afirmam que as transações internacionais de produtos lácteos representam de $5 \%$ a 7\% do total mundial de leite produzido, o que indica uma produção altamente voltada para o consumo interno. Entretanto, ao analisar a evolução do comércio mundial de lácteos durante o início do século XXI, nota-se que houve um elevado crescimento até a crise mundial de 2008, um expressivo decréscimo no ano seguinte à crise e uma retomada dos altos valores comercializados nos anos posteriores (UNComtrade - United Nations Commodity Trade System, 2013). Fatores como a elevação da produção mundial de leite, aumento da renda (sobretudo nos países asiáticos) e mudanças nos hábitos de consumo são responsáveis pela expansão pré-crise e pós-crise, o que torna o comércio mundial de lácteos cada vez mais indispensável para os países exportadores e importadores.

A categoria dos lácteos engloba produtos distintos, com características intrínsecas e comerciais diferentes. Pelas categorias do HS (Harmonized
System) $)^{5}$, disponíveis em UNComtrade (2013), duas classes de produtos lácteos merecem destaque. Os queijos (categoria 0406) representam o derivado lácteo mais exportado mundialmente em termos monetários, tendo alcançado, em 2012, valor próximo de US\$ 25 bilhões. Todavia, o comércio internacional de queijos dá-se, em sua maior parte, entre países da União Europeia, mercado altamente favorável ao comércio intrabloco pela existência do bloco econômico e pela proximidade, além de haver grande diferenciação por produto. Por sua vez, o leite em pó (categoria 0402) é o segundo derivado lácteo mais transacionado mundialmente, alcançando valor exportado, em 2012, de cerca de US\$ 16 bilhões, sendo ainda o produto lácteo menos perecível, mais propício para exportações entre países e comercializado em praticamente todos os continentes. Esta categoria é ainda dividida em leite em pó desnatado (categoria 040210) e leite em pó integral (categorias 040221 e 040229, não adocicado e adocicado, respectivamente).

O comércio internacional de leite em pó, assim como dos lácteos em geral, segue um padrão regionalizado, em que países próximos ou pertencentes ao mesmo bloco econômico tendem a comercializar em maior expressão. A exceção é

5. Harmonized System (HS) corresponde ao sistema de classificação em grupos de todos os produtos comercializados mundialmente. Os derivados lácteos estão contidos no capítulo 04 do HS. 
o continente africano, que produz poucos derivados lácteos e tem no leite em pó uma importante fonte de proteína, por isto realiza importações de diferentes localidades para suprir a demanda interna. Um dos motivos de tal padrão regional deve-se ao fato de a evolução do comércio internacional de leite em pó ser recente e, à medida que o comércio evolui e se consolida, é natural que se estabeleça maior concorrência mundial. Outro motivo seria o alto grau de protecionismo no mercado internacional de lácteos.

Assim exposto, de acordo com UNComtrade (2013), o comércio internacional de leite em pó tem o seguinte padrão no que tange os grandes players de cada continente: países da União Europeia basicamente comercializam entre si e exportam para países africanos tanto o leite em pó integral quanto o desnatado; a Nova Zelândia se caracteriza como o principal exportador mundial de leite em pó integral e tem na China e nos países africanos os principais mercados compradores (sobretudo o primeiro); os Estados Unidos são o principal exportador mundial de leite em pó desnatado, destinando produtos em maior escala para o México; por fim, na América do Sul, tem-se Argentina e Uruguai como os maiores exportadores de ambos os derivados, ao passo que Brasil e Venezuela se caracterizam como os principais destinos, além de países africanos como a Argélia.

A América do Sul, portanto, é um importante mercado de leite em pó integral e desnatado, em que o Brasil atua como um importante importador, e Argentina e Uruguai configuram-se como grandes exportadores. Dados do UNComtrade (2013) demostram que Argentina e Uruguai respondem por cerca de $90 \%$ da exportação de leite em pó integral para o Brasil, ao passo que, com relação ao leite em pó desnatado, essa porcentagem é de $95 \%$. Isto indica um alto grau de concentração em apenas dois países exportadores. Assim, nota-se que ambos os países podem atuar como oligopolistas em estruturas de concorrência imperfeita, o que pode gerar consequências tanto para os países exportadores quanto para o país importador.
Ao caracterizar as estruturas de concorrência dos mercados exportadores de leite em pó integral e desnatado para o Brasil como imperfeitas, é provável que os ofertantes exerçam poder de mercado, termo inicialmente desenvolvido por Lerner (1934) e que representa a capacidade de a indústria/firma praticar um preço acima do custo marginal. De acordo com Martin (2010), em um mercado de concorrência perfeita as empresas igualam seus preços aos custos marginais no longo prazo, o que torna o lucro econômico igual a zero e não há incentivos à entrada ou à saída de ofertantes. Já em mercados imperfeitos há a possibilidade de as empresas cobrarem um preço superior ao custo marginal, auferindo lucros econômicos positivos e possivelmente incorrendo em peso morto. Em outras palavras, o ofertante é capaz de elevar (reduzir) o preço do produto diminuindo (aumentando) a quantidade disponibilizada, ou simplesmente determinando um preço maior graças à sua capacidade de formar preços. Pelo lado da demanda, além da formação do peso morto, definido por Mas Collel et al. (1995) como a redução do bem-estar provocada pela distorção da quantidade consumida com respeito ao equilíbrio competitivo, há também transferência de excedente do consumidor para o produtor

Há indícios de que as firmas argentinas e uruguaias exerçam poder de mercado nas exportações de leite em pó integral e desnatado para o Brasil. As firmas dos dois países supracitados exportam quase a totalidade destes derivados para o território brasileiro, ao passo que há uma regionalização do comércio internacional destes produtos, visto que é um comércio ainda em expansão em que os países tendem a comercializar com parceiros próximos. Da mesma forma, há indícios de barreiras à entrada, já que os custos para produzir leite em pó tendem a ser irrecuperáveis pelo alto grau de especificidade dos ativos, e também indícios de baixas elasticidades preço e preço cruzado. Segundo os cálculos da Fapri (2013), as elasticidades preço da demanda brasileira por leite em pó integral e desnatado são $-0,48$ e - 0,21 , respectivamente, ou seja, se o preço variar em uma determinada magnitude, a reação 
dos consumidores em aumentar ou diminuir a demanda é menos que proporcional à variação do preço.

As questões que favorecem o exercício do poder de mercado por parte das firmas exportadoras são ainda mais relevantes no presente caso, já que o Brasil é um país que ainda registra uma baixa renda per capita e possui problemas relacionados à pobreza e desnutrição. Assim, os leites em pó integral e desnatado são de fundamental importância nutritiva para a população, tanto em consumo final quanto na produção de produtos de maior valor agregado. O Brasil é o maior produtor de leite em pó integral e desnatado da América do Sul, segundo dados da FAO - Food and Agriculture Organization (2013) e da Fapri - Food and Agricultural Policy Research Institute (2013). Todavia, a produção é voltada para abastecer o consumo interno. O país atuou como exportador líquido apenas por breve período entre 2004 e 2008, em que houve uma junção de fatores favoráveis, como preços internacionais em patamares altos, demanda externa aquecida e elevação da produção de leite e derivados. Com a crise econômica mundial em 2008, o Brasil voltou a ser importador líquido de leite e derivados nos anos seguintes, incluindo o leite em pó. Logo, ao contrário de Uruguai e Argentina, o Brasil não é estruturalmente competitivo internacionalmente nas exportações, além de depender fortemente das compras internacionais destes produtos. De acordo com dados do UNComtrade (2013), FAO (2013) e Fapri (2013), cerca de $13 \%$ do consumo brasileiro de leite em pó integral é de produtos importados, ao passo que aproximadamente $22 \%$ do total consumido internamente de leite em pó desnatado provém de outros países. Atestar a presença de poder de mercado e caracterizar os mercados como imperfeitos é relevante no sentido de que as indústrias brasileiras que utilizam o leite em pó para fabricação de outros produtos seriam impactadas significativamente com alterações nos preços, além do fato de que consumidores finais seriam prejudicados com aumentos nos preços via redução da quantidade exportada. Neste contexto, questiona-se se Argentina e Uruguai atuam como formadores de preços e exercem poder de mercado nas exportações de leite em pó integral e desnatado para o Brasil.

Tem-se como objetivo central no presente trabalho caracterizar o grau de concorrência entre Argentina e Uruguai no que tange as exportações de leite em pó integral e desnatado para o Brasil, no período de 2002 a 2013. Para tal, verifica-se se as firmas de ambos os países possuem a capacidade de exercer poder de mercado, confirmando a ausência de concorrência perfeita em caso positivo. Pelos indícios citados anteriormente, a primeira hipótese é de que ambos os países atuam como oligopolistas e exercem poder de mercado nas exportações de leite em pó integral. Da mesma forma, a segunda hipótese considera que ambos também atuam como oligopolistas e exercem poder de mercado nas exportações de leite em pó desnatado para o Brasil.

O mercado relevante em sua vertente geográfica é definido pelas exportações de Argentina e Uruguai para o Brasil. Isto se deve ao fato de a regionalização do comércio exposto anteriormente, ou seja, a concorrência estabelecida e a existência ou não de poder de mercado impactam nestes dois países exportadores e no país de destino. Não é possível afirmar que, por exemplo, as firmas argentinas e uruguaias competem com as exportações da Nova Zelândia, já que não houve importação significativa por parte do Brasil proveniente deste país. Já com relação à sua vertente de produto, o leite em pó integral e o leite em pó desnatado são considerados produtos distintos, participantes de dois mercados diferentes. Considera-se não ser adequado agrupar os dois derivados no mesmo produto "leite em pó" para as estimações pelo fato de um possuir um nível de gordura animal deveras superior ao outro, além de serem utilizados para consumo final e como insumos para diferentes fins (o leite em pó desnatado é mais relacionado a produtos dietéticos ou com menor teor de gordura).

Com relação à literatura, a estimação do poder de mercado tem sido uma importante preocupação da literatura econômica, incluindo o 
setor agropecuário e alimentício ${ }^{6}$. Mais especificamente, o trabalho de Goldberg e Knetter (1999) desenvolve e utiliza a metodologia de demanda residual aplicada no presente trabalho, mensurando o poder de mercado e a intensidade da concorrência nos mercados exportadores de cerveja na Alemanha e de papelão nos Estados Unidos. Bragança (2003) aplica a metodologia desenvolvida na mensuração do poder de mercado nas exportações de café brasileiro para os Estados Unidos, ao passo que Coronel et al. (2011) estimam o poder de mercado nas exportações de farelo de soja para a União Europeia.

O artigo está organizado da seguinte forma: a segunda seção é referente à metodologia utilizada para estimar o poder de mercado e caracterizar o grau de concorrência entre os países exportadores, a terceira seção é referente aos resultados e discussões e a quarta seção é dedicada às conclusões do trabalho.

\section{Metodologia}

\subsection{Aspectos teóricos do modelo de demanda residual}

O presente trabalho utiliza o modelo de demanda residual proposto por Goldberg e Knetter (1999) para a estimação do poder de mercado. Baseando-se no modelo desenvolvido por Baker e Bresnaham (1988), proveniente da Nova Organização Industrial Empírica (NOIE), Goldberg e Knetter (1999) procuraram adaptar a metodologia para o comércio internacional, aproveitando as vantagens deste modelo na estimação do poder de mercado com dados de países, e não de firmas. Desta forma, considera-se que esta metodologia é a mais adequada para o presente caso quando comparada com metodologias não

6. Alguns exemplos recentes são: Aguiar e Figueiredo (2011), que analisam o poder de mercado no varejo alimentar no estado de São Paulo; Profeta e Braga (2011), que verificam o poder de mercado na indústria brasileira de fertilizantes; Cakir e Balagtas (2012), que estimam o poder de mercado das cooperativas de leite fluido nos Estados Unidos. específicas para o comércio exterior, como Baker e Bresnaham (1988) e Steen e Salvanes (1999).

Inicialmente, considera-se um grupo de firmas que exportam um produto homogêneo para um determinado mercado de destino, compondo um país exportador, ao mesmo tempo em que as firmas exportadoras dos demais países concorrentes compõem os países que competem com o primeiro no mercado de destino. As funções de demanda do país exportador e de seus concorrentes podem ser expressas da seguinte forma:

$$
\begin{aligned}
& p^{e x}=D^{e x}\left(Q^{e x}, p^{1}, \ldots, p^{n}, Z\right) \\
& p^{k}=D^{k}\left(Q^{k}, p^{j}, \ldots, p^{e x}, Z\right)
\end{aligned}
$$

em que $j=1, \ldots, n$ e $j \neq k$

A equação (1) representa a função de demanda inversa dos bens do país exportador em questão, em que $p^{e x}$ é o preço do bem exportado, $Q^{e x}$ a quantidade exportada pelo país exportador para o mercado de destino, $p^{1} \ldots p^{n}$ são os preços dos bens dos demais países competidores e $Z$ é um vetor de deslocadores da demanda do país importador. A equação (2) é similar à anterior, porém, para os demais países concorrentes $k$.

Cada firma $i$ do país exportador possui o seguinte problema de maximização:

$$
\max q_{i}^{e x} \prod_{i}^{e x}=p^{e x} q_{i}^{e x}-e C_{i}^{e x}
$$

Em que $e$ é a taxa de câmbio, $C_{i}^{e x}$ o custo de cada firma $i$ do país exportador, $q_{i}^{e x}$ é a quantidade exportada por cada firma do país exportador e $\pi_{i}^{e x}$ é o lucro de cada firma. A condição de primeira ordem para cada firma implica que o custo marginal seja igual à receita marginal, ou seja:

$$
\begin{aligned}
& p^{e x}=e \times C m g_{i}^{e x}-q_{i}^{e x} \times \\
& \times D_{1}^{e x}\left(1+\sum_{j \neq i} \frac{\partial q_{j}^{e x}}{\partial q_{i}^{e x}}\right)\left(1+\sum_{j \neq i} \frac{\partial D^{e x}}{\partial p^{k}} \times \frac{\partial D^{k}}{\partial p^{e x}}\right)
\end{aligned}
$$

Em que $C m_{g_{i}}{ }^{e x}$ é o custo marginal de cada firma do país exportador em questão e $D_{1}^{e x}$ é a derivada parcial da função de demanda relativa ao primeiro argumento. $\mathrm{O}$ primeiro termo entre parênteses representa o comportamento competitivo entre as firmas do país exportador, 
enquanto o segundo termo entre parênteses captura a interação estratégica entre as firmas do país exportador e as firmas dos países concorrentes. Denotando o primeiro termo e o segundo termo entre parênteses de $\theta_{i}$ e $\phi$ respectivamente, tem-se:

$$
p^{e x}=e \times C m g_{i}^{e x}-q_{i}^{e x} \times D_{1}^{e x} \times \theta_{i}^{e x} \times \varnothing^{e x}
$$

Nota-se que, para resolver o problema de igualdade entre o custo marginal e a receita marginal são necessários dados das firmas, já que há a interação estratégica entre as firmas do país exportador e também entre as firmas do país exportador em relação às firmas dos países concorrentes. Para realizar a agregação e permitir que sejam utilizados dados de países, pressupõe-se que os parâmetros sejam médias das firmas, ponderados pelo peso das parcelas de mercado de cada firma. Devido à agregação, as expressões "Argentina" e "firmas argentinas" são consideradas sinônimas. Assim, multiplicando (5) pela parcela de mercado $s_{i}$ de cada firma e aplicando o somatório, tem-se:

$$
\begin{aligned}
& \sum_{i} s_{i} \times p^{e x}=\sum_{i} s_{i} \times e \times C m g_{i}^{e x}- \\
& -\sum_{i} s_{i} \times q_{i}^{e x} \times D_{1}^{e x} \times \theta_{i}^{e x} \times \varnothing^{e x}
\end{aligned}
$$

Considerando que $\sum_{i} s_{i}=1$ e $q_{i}^{e x}=s_{i} x Q^{e x}$, obtém-se a versão transformada da condição de primeira ordem possível de ser estimada com dados de países:

$$
p^{e x}=e \times C m g^{e x}-Q^{e x} \times D_{1}^{e x} \times \theta^{e x} \times \varnothing^{e x}
$$

em que $C m g^{e x}=\sum_{i} s_{i} x C m g_{i}^{e x}$ e $\theta^{e x}=\sum_{i} s_{i}^{2} x \theta_{i}^{e x}$. Similarmente, os demais países competidores possuem a seguinte condição de primeira ordem transformada:

$$
p^{k}=e^{k} \times C m g^{k}-Q^{k} \times D_{1}^{k} \times \vartheta^{k}
$$

em que $\vartheta^{k}=\theta^{k} x \phi^{k}$ e $k=1, \ldots, n$

Até o momento, observa-se a generalidade das derivações. As funções de demanda são arbitrárias, de modo que os produtos exportados por firmas de países diferentes podem ou não serem substitutos perfeitos, ao mesmo tempo em que as curvas de oferta são gerais e os parâmetros que capturam as interações estratégicas podem variar de zero até um cartel perfeito. Em adição, nenhuma pressuposição foi realizada acerca do custo marginal, podendo ser constantes ou não.

Nos métodos tradicionais da Nova Organização Industrial Empírica (NOIE), tal como discutido em Bresnahan (1989), os sistemas de equações (2) - (8) devem ser estimados para que se obtenham os parâmetros de poder de mercado. Isto implica em especificar formas funcionais e estimar as funções de demanda, custos e os parâmetros de conduta com dados da indústria. O presente modelo difere dos métodos tradicionais pelo fato de as estimações se relacionarem a apenas a uma equação: a curva de demanda residual do país exportador.

Em primeiro lugar, considera-se o sistema de equação composto por (2) - (8) relacionados aos $n$ países competidores. Resolvendo para os preços e quantidades dos $n$ países competidores e considerando que o custo marginal $\left(\mathrm{Cmg}^{k}\right)$ de cada concorrente é uma função da quantidade produzida $\left(Q^{k}\right)$ e dos deslocadores de custos $\left(W^{k}\right)$, a equação (8) pode ser expressa por:

$$
\begin{aligned}
& p^{k}=e^{k} \times C m g^{k}\left(Q^{k}, W^{k}\right)-Q^{k} \times \\
& \times D_{1}^{k}\left(Q^{k}, p^{j}, p^{e x}, Z\right) \times \vartheta^{k}
\end{aligned}
$$

Em adição, resolvendo o sistema de 2 n equações definidas por (2) - (8), é possível obter também os preços dos competidores como função dos deslocadores de custos e dos deslocadores de demanda para todos os concorrentes e da quantidade exportada pelo país exportador em questão $\left(Q^{e x}\right)$. Denotando $W^{N}$ como a união dos deslocadores de custos de todos os concorrentes e $\vartheta^{N}$ a união de todos os parâmetros de condutas dos concorrentes, tem-se:

$$
p^{k}=p^{k^{*}}\left(Q^{e x}, W^{N}, Z, \partial^{N}\right)
$$

em que $k=1, \ldots, n$

Cada $p^{k *}$ é uma forma parcial reduzida, em que a única variável endógena no lado direito é $Q^{e x}$. A dependência de $p^{k}$ de $Q^{e x}$ vem do fato de que apenas as equações relacionadas aos concorrentes foram resolvidas. Para obter a demanda 
residual do país exportador em questão, devem-se substituir as $n$ expressões definidas em (11) em (2), desta forma eliminando os preços dos concorrentes:

$$
\begin{aligned}
& p^{e x}=D^{e x}\left(Q^{e x}, p^{1^{*}}, \ldots, p^{n^{*}}, Z\right)= \\
& =D^{r e s, e x}\left(Q^{e x}, W^{N}, Z, \vartheta^{N}\right)
\end{aligned}
$$

Assim, a demanda residual possui três argumentos observáveis: a quantidade exportada pelo conjunto de firmas do país exportador em questão, deslocadores de demanda do mercado de destino e deslocadores dos custos dos países concorrentes.

Para compreender a relação entre a elasticidade da demanda residual e o grau de poder de mercado, realiza-se o procedimento de logaritmo e diferencia-se com relação a $Q^{e x}$. Deste modo, tem-se:

$\varepsilon_{D R}=\frac{\partial \ln D^{r e s, e x}}{\partial \ln Q^{e x}}=\frac{\partial \ln D^{e x}}{\partial \ln Q^{e x}}+\sum_{k} \frac{\partial \ln D^{e x}}{\partial \ln p^{k^{*}}} \times \frac{\partial \ln p^{k^{*}}}{\partial \ln Q^{e x}}$

A derivada $\partial \ln p^{k^{*}} / \partial \ln Q^{e x}$ representa as respostas dos preços dos concorrentes em relação a variações na quantidade do país exportador em questão, ao passo que $\varepsilon_{D R}$ representa a elasticidade da demanda residual do mesmo país exportador. Pela condição de primeira ordem (8) é possível verificar que a elasticidade da demanda residual é igual ao poder de mercado $\left(p^{e x}-C m g^{e x}\right) /$ $p^{e x}$ se e somente se a curva de demanda residual coincidir com a conjectural, ou seja, o país exportador em questão leva em consideração as interações estratégicas e as respostas dos concorrentes a seus atos.

Em alguns casos, a condição supracitada é perfeitamente satisfeita, como salienta Baker e Bresnahan (1988). Pode-se citar o caso em que há uma firma dominante e pequenos concorrentes, já que neste caso a firma dominante saberia que a curva de oferta dos concorrentes afetaria a demanda e, portanto, ela agiria considerando esta questão. Outros dois casos são quando há competição perfeita e grande diferenciação do produto. No primeiro, o preço da firma é determinado pelo preço dos competidores e a elasticidade da demanda residual é zero, indicando que o poder de mercado também é zero e fazendo com que a curva de demanda residual coincida com a conjectural. No segundo, a distinção entre variação conjectural e a curva de demanda residual é menos relevante, visto que não há substitutibilidade perfeita entre os produtos. Intuitivamente, uma firma teria poder de mercado pela diferenciação do seu produto, e não por questões estratégicas relacionadas a preços e quantidades.

Em outros equilíbrios de oligopólio pode não haver uma correspondência exata entre o Índice de Lerner e a elasticidade da demanda residual; entretanto, é razoável supor que uma curva de demanda residual mais inclinada indique maior poder de mercado, ou seja, maior capacidade de manter o preço acima do custo marginal. Por fim, vale ressaltar que a elasticidade da demanda residual incorpora dois aspectos: a demanda do mercado e a oferta dos demais concorrentes. Portanto, nos casos em que o Índice de Lerner possa ser difícil de ser estimado diretamente por diversas questões relacionadas à definição de mercado, ausência de dados plausíveis e dificuldades de estimação dos custos marginais, a elasticidade da demanda residual fornece uma alternativa interessante.

\subsection{Referencial analítico}

\subsubsection{Estimação da demanda residual}

Dado o referencial teórico do modelo de demanda residual, tem-se como objetivo utilizar as variáveis resultantes da derivação algébrica em (11) para estimar uma demanda residual para cada país exportador e cada um dos tipos de leite em pó. Assim, estima-se a elasticidade da demanda residual que, como visto anteriormente, é uma interessante aproximação da distância entre o preço e o custo marginal, ou seja, do poder de mercado.

Os grupos de variáveis que deslocam a demanda residual em (11) são: a quantidade exportada pelo país exportador $\left(Q^{e x}\right)$, deslocadores de custos dos países concorrentes $\left(W^{N}\right)$ e os deslocadores de demanda do país importador $(Z)$. 
Assim como em Goldberg e Knetter (1999), Bragança (2005) e Coronel et al. (2010), opta-se por estimar as funções de demanda residual na forma $\log$-log, pois, assim, são obtidas as elasticidades diretamente. As equações a serem estimadas possuem a seguinte forma geral:

$\ln p_{t}^{e x}=\varphi+\varepsilon_{D R} \ln Q_{t}^{e x}+\alpha^{\prime} \ln Z_{t}+\beta^{\prime} \ln W_{t}^{N}+\sigma_{t}$

Em que $\varphi$ é a constante da regressão, $\varepsilon_{D R}$ é a elasticidade da demanda residual, $\alpha^{\prime}$ e $\beta^{\prime}$ são vetores de parâmetros correspondentes aos grupos de variáveis $Z_{t}$ e $W_{t}^{N}$, respectivamente, e $\sigma_{t}$ é o termo de erro da equação. No presente trabalho, a equação (13) é estimada para Argentina e Uruguai, visto que ambos concorrem com relação às exportações de leite em pó integral e desnatado para o Brasil, sendo este o mercado importador. Assim, quatro equações são estimadas, uma para cada país exportador e cada derivado lácteo em questão, como definido na questão do mercado relevante ${ }^{7}$.

$O$ parâmetro de maior interesse é $\varepsilon_{D R}$, que representa a elasticidade da demanda residual e é obtida diretamente devido à forma funcional escolhida para estimação. Caso $\varepsilon_{D R}$ não seja estatisticamente diferente de zero é indicado que o país exportador atua como em concorrência perfeita, em que o grupo de firmas que compõe este país se defronta com uma demanda perfeitamente elástica, ou seja, o preço recebido não depende da quantidade exportada, mas, sim, dos custos dos concorrentes apenas. Por outro lado, caso a elasticidade da demanda residual seja estatisticamente significativa, quanto maior em termos absolutos, maior é a diferença entre os preços e o custo marginal, indicando maior poder de mercado exercido pelas firmas e, consequentemente, pelo país exportador.

Com relação aos grupos de variáveis, os deslocadores de demanda do país importador $\left(Z_{t}\right)$

7. Isto resulta nas equações (14), (15), (16) e (17) a seguir que, apesar de serem semelhantes e terem o mesmo objetivo (estimar um parâmetro referente ao poder de mercado), as duas primeiras referem-se às exportações de leite em pó integral de Argentina e Uruguai, respectivamente, ao passo que as duas últimas são referentes às exportações de leite em pó desnatado da Argentina e Uruguai para o Brasil. podem ser variáveis relacionadas à renda da população, produção da indústria, taxa de câmbio, entre outros. Já os custos dos concorrentes podem ser expressos por variações nos preços da matéria-prima, custos de mão de obra e também da taxa de câmbio. Para Goldberg e Knetter (1999), a vantagem de utilizar a taxa de câmbio como deslocador de custos é a variabilidade, já que mesmo que não haja variação em outros aspectos relacionados aos custos dos concorrentes provavelmente a taxa de câmbio continuará demonstrando alterações, o que impacta significativamente os incentivos à exportação.

Desta forma, as funções de demanda residual a serem estimadas das exportações de leite em pó integral de Argentina e Uruguai têm a seguinte forma, respectivamente:

$$
\begin{aligned}
& \ln p_{t}^{\mathrm{arg}}=\varphi_{1}+\delta_{1} \ln p_{t-1}^{\mathrm{arg}}+\varepsilon_{D R_{1}} \ln Q_{t}^{\mathrm{arg}}+ \\
& +\alpha_{1} \ln e_{t}^{b r}+\alpha_{2} \ln I C S_{i}^{b r}+\beta_{1} \ln e_{t}^{u r u}+ \\
& +\beta_{2} \ln e_{t-1}^{u r u}+\mu_{1} T_{i}+\sigma_{t_{1}} \\
& \ln p_{t}^{u r u}=\varphi_{2}+\delta_{2} \ln p_{t-1}^{u r u}+\varepsilon_{D R_{2}} \ln Q_{t}^{u r u}+ \\
& +\alpha_{3} \ln I C S_{i}^{b r}+\beta_{3} \ln I P P_{t}^{\mathrm{arg}}+\sigma_{t_{2}}
\end{aligned}
$$

Nota-se que as variáveis dependentes defasadas e as variáveis explicativas defasadas em um período são utilizadas como variáveis explicativas. Elas são utilizadas tanto nas funções de demanda residual quanto na instrumentalização da quantidade exportada. Isto é justificado pelo fato de que no comércio internacional as compras e vendas são feitas por contratos e não são instantâneas, ou seja, uma variação na taxa de câmbio de um país no período atual pode ter influência na quantidade vendida e nos preços de exportação apenas no mês posterior, por exemplo. $\mathrm{O}$ contrato teria sido feito no mês corrente, porém, o registro da exportação ocorreria apenas quando o produto chegasse ao país de destino.

Em (14), $p^{\text {arg }}$ representa o preço de exportação da Argentina, $Q^{\text {arg }}$, a quantidade exportada, $e^{b r}$, a taxa de câmbio nominal do Brasil, ICS ${ }^{b r}$, o índice de comércio nos supermercados brasileiros, $e^{u r u}$, a taxa de câmbio nominal do Uruguai e $T$, a tendência. Já em (15), $p^{u r u}$ e $Q^{u r u}$ representam 
o preço de exportação e a quantidade exportada pelo Uruguai respectivamente, ao passo que ICS ${ }^{b r}$ simboliza o índice de comércio nos supermercados brasileiros e IPPrrg, o índice de preço ao produtor - Gado e Leite da Argentina.

Com relação às funções de demanda residual das exportações de leite em pó desnatado a serem estimadas, as mesmas possuem o seguinte formato para Argentina e Uruguai, respectivamente:

$$
\begin{aligned}
& \ln p_{t}^{\mathrm{arg}}=\varphi_{3}+\delta_{3} \ln p_{t-1}^{\mathrm{arg}}+\varepsilon_{D R_{3}} \ln Q_{t}^{\mathrm{arg}}+ \\
& +\alpha_{4} \ln I C S_{i}^{b r}+\beta_{4} \ln e_{t}^{u r u}+\beta_{5} \ln P P_{t}^{u r u}+ \\
& +\mu_{2} T_{i}+\sigma_{t_{3}} \\
& \ln p_{t}^{u r u}=\varphi_{4}+\delta_{4} \ln p_{t-1}^{u r u}+\varepsilon_{D R_{4}} \ln Q_{t}^{u r u}+ \\
& +\alpha_{5} \ln I C S_{i}^{b r}+\beta_{6} \ln e_{t}^{\mathrm{arg}}+\sigma_{t_{4}}
\end{aligned}
$$

Em (16) as variáveis $p^{\text {arg }}$ e $Q^{\text {arg }}$ representam o preço de exportação e a quantidade exportada na ordem exposta, enquanto ICS ${ }^{b r}$, $e^{u r u}$ e PPuru são o índice de comércio nos supermercados brasileiros, o câmbio nominal do Uruguai e o preço do leite ao produtor no Uruguai, respectivamente. $T$ é a tendência incluída na estimação. Por fim, na equação (17), $p^{u r u}$ é o preço de exportação, $Q^{u r u}$, a quantidade exportada, ICS ${ }^{b r}$, o índice de comércio nos supermercados brasileiros e $e^{\text {arg }}$, a taxa de câmbio nominal na Argentina.

As quantidades exportadas $\left(Q^{e x}\right)$ são endógenas com relação aos preços de exportação $\left(P^{e x}\right)$ em suas respectivas funções de demanda residual e, por isso, devem ser instrumentalizadas. Como os custos do próprio país exportador são excluídos da equação, estes podem ser utilizados como instrumentos, ou seja, variáveis correlacionadas com quantidade exportada e que não estão inclusas na respectiva função de demanda residual. A taxa de câmbio do país exportador é uma forte candidata a instrumento, já que apresenta alta variabilidade e é um importante deslocador de custos do país exportador.

Cabe ressaltar que a crise econômica mundial no final de 2008 impactou severamente as transações internacionais. No presente trabalho, uma dummy relacionada à crise foi incluída para verificar se a mesma impactou significativamente nas exportações argentinas e uruguaias de leite em pó integral e desnatado para o Brasil. Todavia, a dummy não se mostrou significativa nas estimações, por isto, optou-se por desconsiderá-la das funções de demanda residual. De fato, analisando os dados da amostra, verifica-se que não houve uma mudança abrupta nos padrões de exportações de leite em pó para o Brasil.

\subsubsection{Procedimentos econométricos}

As funções de demanda residual são estimadas por três métodos distintos: mínimo quadrado de dois estágios (MQ2E), Seemingly Unrelated Regressions (SUR) e mínimo quadrado de três estágios (MQ3E). Pelo fato de considerar tanto a endogeneidade entre preço e quantidade e a possível correlação entre os erros, o presente trabalho considera que os resultados mais importantes são referentes às estimações por MQ3E, e por isto estes são analisados. Para maior aporte teórico, o teste de Wu-Hausman é realizado no MQ2E com o intuito de verificar se a variável "quantidade" é, de fato, endógena, ao passo que o teste do Multiplicador de Lagrange (ML) de BreuschPagan $^{8}$ para a possível correlação contemporânea entre os termos de erro em sistemas de equações é realizado no MQ3E, com o intuito de verificar se realmente é necessário levar tal fato em consideração nas estimações. Assim, os outros métodos funcionam como um teste de robustez econométrica e para mostrar como as estimativas que não levam em consideração a endogeneidade e a possível correlação entre os erros podem apresentar resultados viesados.

São realizados os testes de Pagan-Hall e Cumby-Huizinga para verificar a presença ou não de heterocedasticidade e autocorrelação, respectivamente. Estes testes foram propostos por Pagan e Hall (1983) e Cumby e Huizinga (1992) e consideram a presença de heterocedasticidade e autocorrelação em métodos que utilizem varáveis instrumentais, tal como o MQ2E. Em ambos a hipótese nula é de ausência de hetero-

8. Para detalhes do teste, ver Shehata (2012). 
cedasticidade e autocorrelação respectivamente, portanto, o objetivo é não rejeitar a hipótese nula. Em adição, realiza-se os testes de Sargan e Hansen-Sargan para testar a validade dos instrumentos utilizados no MQ2E e MQ3E, respectivamente, assim como em Goldberg e Knetter (1999), Bragança (2003) e Coronel et al. (2011). O software STATA 12 é utilizado nas estimações.

\subsubsection{Fonte de dados}

A estimação da demanda residual para cada país (Argentina e Uruguai) e cada produto (leite em pó integral e desnatado) requer cinco categorias de variáveis: o preço de exportação, dado pela razão entre o valor e a quantidade exportada; a quantidade exportada, que está relacionada ao parâmetro de demanda residual e ao poder de mercado exercido pelo país exportador; os deslocadores de custos do país concorrente; os deslocadores de demanda do país importador e, por fim, os deslocadores de custos do próprio país exportador, utilizado para instrumentalizar a quantidade exportada, dada a endogeneidade em relação aos preços no métodos de MQ2E e MQ3E.

Para o presente trabalho, os dados são mensais e compreendem o período de janeiro de 2002 a julho de 2013. Este período foi definido devido à disponibilidade dos dados e pelo fato de que, com exceção da crise econômica mundial em 2008, foi um período de relativa estabilidade mundial, com o comércio internacional e as economias dos países em constante expansão, em sua maioria. Incluir anos anteriores poderia exigir maior controle econométrico de diversas crises e variações estruturais nos países em questão, como a crise econômica na Argentina em 1999 e a opção pelo câmbio flutuante no Brasil também em 1999, por exemplo. Isto não seria interessante e não está no foco do presente trabalho, visto que o interesse é analisar a existência de poder de mercado no período recente.

Deste modo, os preços de exportação (US\$/kg) e as quantidades exportadas $(\mathrm{Kg})$ foram obtidos no Sistema Aliceweb (2013). Optou-se por obter estas variáveis na forma de preço de importação e quantidade importada pelo Brasil, visto que, desta forma, é considerado o que realmente foi registrado ao chegar no país de destino. Espera-se que o coeficiente relacionado à quantidade exportada (elasticidade da demanda residual) seja negativo, visto que, quanto maior as exportações, menores tendem a ser os preços.

As variáveis relacionadas aos custos do Uruguai são: Preço do Leite ao Produtor (US\$/ litro) e Taxa de Câmbio Nominal (peso uruguaio/ US\$). O primeiro foi obtido por meio do Inale Instituto Nacional de la Leche (2013), enquanto o segundo foi disponibilizado pelo Ipeadata (2013). Teoricamente, espera-se que o coeficiente do Preço do Leite ao Produtor do Uruguai seja positivo, já que uma elevação aumentaria os custos da indústria uruguaia para obter matéria-prima, fazendo com que a Argentina possa também elevar seus preços e manter-se competitiva. Com relação à Taxa de Câmbio Nominal do Uruguai, espera-se um coeficiente negativo, visto que uma valorização do câmbio (diminuição da taxa de câmbio nominal) tende a aumentar os custos e os preços de exportação das firmas uruguaias, o que induz as firmas argentinas a também elevarem seus preços. Do contrário, uma desvalorização cambial tornaria os custos e os preços de exportação menores no Uruguai, pressionando para que a Argentina também reduzisse seus preços de exportação.

As variáveis que representam os deslocadores de custos de produção da Argentina são: Índice de Preço ao Produtor - Gado e Leite (IPP - Gado e Leite) e Taxa de Câmbio Nominal (Peso Argentino/US\$), sendo o primeiro disponibilizado por Indec (2013), e o segundo, por Ipeadata (2013). O coeficiente relacionado ao IPP - Gado e Leite tende a ser positivo, já que um aumento representaria maiores custos para a indústria argentina e poderia fazer com que as empresas do Uruguai também elevassem seus preços. Por outro lado, a Taxa de Câmbio Nominal da Argentina tende a apresentar coeficiente negativo, pelos mesmos motivos expostos no caso da Taxa de Câmbio do Uruguai. 
Por fim, os deslocadores de demanda do Brasil são: Taxa de Câmbio Nominal (R\$/US\$) e Índice de Comércio nos Supermercados, obtidos em Ipeadata (2013) e IBGE (2013) respectivamente. Espera-se que o coeficiente do primeiro seja positivo, visto que uma desvalorização da Taxa de Câmbio brasileira prejudicaria as importações, reduzindo a quantidade importada e incrementando os preços. O segundo, por sua vez, também tende a apresentar um coeficiente positivo, já que quanto maior a atividade comercial no ramo do varejo e atacado maior tende a ser a demanda pela importação, o que impacta positivamente nos preços.

Duas importantes ressalvas devem ser feitas com relação aos dados. Em alguns meses da amostra não foi registrada exportação de leite em pó integral e desnatado do Uruguai para o Brasil. Assim, a variável quantidade exportada teria o valor de "zero", bem como o preço de exportação. Todavia, a definição da função de demanda residual implica que, quando a quantidade é zero, o preço resultante da interseção da oferta dos concorrentes e da demanda é o maior possível naquele período, chegando a restringir a compra por parte do demandante (tal como em Goldberg e Knetter, (1999)). Desta forma, após janeiro de 2007, os valores dos preços nulos foram substituídos pelos preços mensais de exportação praticados pelo Uruguai para os todos os países importadores, dados estes obtidos em Aliceweb Mercosul (2013). Antes deste período, foi utilizada a média anual do preço de exportação das firmas uruguaias para o Brasil, disponibilizado por UNComtrade (2013).

\section{Resultados e discussões}

\subsection{Análise descritiva dos dados}

Como visto no tópico anterior, as variáveis são divididas em: preços de exportação e quantidades exportadas de leite em pó integral e desnatado de Argentina e Uruguai para o Brasil, deslocadores de custos de Argentina e Uruguai e deslocadores de demanda do Brasil. Estas variáveis compõem os cinco grupos de cada função de demanda residual estimada. Na Tabela 1 estão presentes as estatísticas descritivas gerais de cada variável.

As quatro primeiras variáveis referem-se aos preços de exportação e estão expressos em dólares por quilograma. Nota-se que, em relação à média, a Argentina pratica um preço superior ao Uruguai tanto no leite em pó integral quanto no desnatado, porém, com relação ao valor máximo da amostra, o Uruguai apresenta os maiores

Tabela 1. Estatísticas descritivas das variáveis

\begin{tabular}{lcccc}
\hline \multicolumn{1}{c}{ Variável } & Média & Desvio padrão & Valor mín. & Valor máx. \\
\hline Preço de exp. de leite em pó int. - Argentina (US\$/kg) & 2,8 & 1,0 & 1,4 & 4,71 \\
Preço de exp. de leite em pó int. - Uruguai (US\$/kg) & 2,7 & 0,9 & 1,4 & 4,76 \\
Preço de exp. de leite em pó des. - Argentina (US\$/kg) & 2,9 & 0,9 & 1,4 & 5,03 \\
Preço de exp. de leite em pó des. - Uruguai (US\$/kg) & 2,7 & 1,0 & 1,3 & 5,26 \\
Quant. exp. de leite em pó int. - Argentina (mil ton.) & $2.256,2$ & $1.515,3$ & 339,5 & $9.285,0$ \\
Quant. exp. de leite em pó int. - Uruguai (mil ton.) & $1.142,5$ & $1.223,9$ & 0,0 & $7.630,0$ \\
Quant. exp. de leite em pó des. - Argentina (mil ton.) & 443,7 & 358,2 & 28,0 & $1.846,7$ \\
Quant. exp. de leite em pó des. - Uruguai (mil ton.) & 591,6 & 861,1 & 0,0 & $4.896,0$ \\
Taxa de câmbio nominal - Argentina (peso arg./US\$) & 3,4 & 0,7 & 1,4 & 5,42 \\
Taxa de câmbio nominal - Uruguai (peso uru./US\$) & 22,8 & 3,6 & 14,3 & 29,8 \\
Índice de preço ao produtor - Gado e Leite - Argentina & 386,9 & 165,9 & 87,2 & 697,2 \\
Preço do leite ao produtor - Uruguai (US\$/litro) & 0,2 & 0,1 & 0,1 & 0,4 \\
Taxa de câmbio nominal - Brasil (R\$SS\$) & 2,2 & 0,5 & 1,6 & 3,8 \\
Índice de comércio nos supermercados - Brasil & 81,8 & 17,5 & 56,7 & 135,9 \\
\hline
\end{tabular}

Fonte: Resultados de pesquisa. 
preços praticados. As quatro variáveis posteriores referem-se às quantidades exportadas em mil toneladas. Verifica-se que, na média, as exportações da Argentina para o Brasil com relação ao leite em pó integral são quase o dobro da média registrada pelo Uruguai, ao passo que as exportações do Uruguai de leite em pó desnatado são cerca de 30\% superiores às da Argentina, em média. Outro fato interessante é que as quantidades exportadas pelo Uruguai, tanto de leite em pó integral quanto desnatado, apresentam desvios padrão superiores que a média, indicando alta variabilidade dos dados, ou seja, em determinados meses há grandes quantidades importadas pelo Brasil de firmas uruguaias, enquanto em outros a quantidade é bastante reduzida.

As quatro próximas variáveis representam os custos dos países exportadores, que funcionam tanto como deslocadores de custos do concorrente na função do outro competidor quanto para instrumentalização da quantidade exportada na função de demanda residual do próprio país. Um fato interessante é que o Uruguai apresenta uma taxa de câmbio nominal desvalorizada em comparação com a Argentina, que por sua vez é mais desvalorizada que o Brasil, em média. Assim, em comparação com o Brasil, o câmbio auxilia para que as firmas argentinas e uruguaias tenham custos de produção de leite em pó menores, sendo o Uruguai em maior magnitude. Por fim, as duas últimas variáveis representam os deslocadores de demanda do Brasil.

Deve ser ressaltado que as estatísticas das variáveis foram retratadas na Tabela 1 em sua forma natural. Todavia, o logaritmo é aplicado em todos os dados para as estimações posteriores.

\subsection{Estimativas das funções de demanda residual}

\subsubsection{Argentina}

As estimativas da função de demanda residual para as exportações de leite em pó integral provenientes da Argentina para o Brasil estão contidas na Tabela 2.
Inicialmente, o modelo foi estimado por MQ2E, utilizando como instrumentos para a quantidade exportada pela Argentina as seguintes variáveis: taxa de câmbio nominal da Argentina atual e defasada um período; taxa de câmbio nominal do Uruguai atual e defasada um período; taxa de câmbio nominal brasileira; IPP - Gado e Leite da Argentina defasado um período e uma variável de tendência. Desta forma, os instrumentos estão relacionados aos deslocadores de custos do país exportador, deslocadores de custos do país concorrente e a variações na demanda brasileira, representada pela taxa de câmbio nominal do Brasil. O teste de Sargan apresentou um $p$-valor de aproximadamente 0,85 , não rejeitando a hipótese nula de que os instrumentos sejam válidos, ao passo que os testes de Pagan-Hall e Cumby-Huizinga registraram p-valores de 0,998 e 0,12, ambos não rejeitando a hipótese nula de ausência de heterocedasticidade e autocorrelação respectivamente. Por fim, o teste de Wu-Hausman rejeita a hipótese nula de que a quantidade exportada pela Argentina seja exógena com p-valor de 0,005, indicando que a instrumentalização da mesma é necessária para obter estimativas consistentes.

O segundo método estimado foi o SUR, em que as funções de demanda residual da Argentina e do Uruguai são estimadas conjuntamente, levando em consideração possíveis correlações entre os termos de erro. Por fim, ao estimar a função de demanda residual para as exportações argentinas de leite em pó integral por MQ3E, nota-se que a elasticidade da demanda residual aumenta consideravelmente em magnitude em relação aos métodos anteriores, além de manter-se significativa e com o sinal esperado. O teste de Hansen-Sargan valida os instrumentos utilizados a $5 \%$ de significância, e o $\mathrm{R}^{2}$ indica um bom ajuste do modelo. O teste LM de Breusch-Pagan rejeita a hipótese nula de que não há correlação contemporânea entre os erros das equações a $1 \%$ de significância, ou seja, o MQ2E não é adequado por não levar esta questão em consideração, ao mesmo tempo em que o SUR também não é adequado por não levar em conta a questão da endogeneidade. 
Tabela 2. Estimativas da função de demanda residual das exportações argentinas de leite em pó integral entre janeiro de 2002 a julho de 2013

\begin{tabular}{|c|c|c|c|}
\hline Método & MQ2E & SUR & MQ3E \\
\hline $\mathrm{R}^{2}$ & 0,989 & 0,972 & 0,964 \\
\hline Constante & $\begin{array}{l}-3,697 \\
-3,319 \\
\end{array}$ & $\begin{array}{c}0,788^{* *} \\
(0,357)\end{array}$ & $\begin{array}{c}2,498^{* * * *} \\
(0,870)\end{array}$ \\
\hline${ }^{1}$ Quantidade exportada - Argentina & $\begin{array}{c}0,173 \\
(0,157) \\
\end{array}$ & $\begin{array}{c}0,046^{* * *} \\
(0,010)\end{array}$ & $\begin{array}{c}-0,131^{* * *} \\
(0,038) \\
\end{array}$ \\
\hline${ }^{1}$ Preço de exportação defasado - Argentina & $\begin{array}{c}1,118^{* * *} \\
(0,193)\end{array}$ & $\begin{array}{c}0,855^{* * *} \\
(0,028)\end{array}$ & $\begin{array}{c}0,767^{* * *} \\
(0,055)\end{array}$ \\
\hline${ }^{2}$ Taxa de câmbio nominal - Uruguai & $\begin{array}{c}-0,034 \\
(0,328) \\
\end{array}$ & $\begin{array}{c}0,169 \\
(0,146)\end{array}$ & $\begin{array}{c}0,208 \\
(0,182) \\
\end{array}$ \\
\hline${ }^{2}$ Taxa de câmbio nominal defasado - Uruguai & $\begin{array}{c}0,588 \\
(0,553) \\
\end{array}$ & $\begin{array}{l}-0,157 \\
(0,131)\end{array}$ & $\begin{array}{c}-0,403^{* *} \\
(0,196)\end{array}$ \\
\hline 3́́ndice de comércio nos supermercados - Brasil & $\begin{array}{l}-0,073 \\
(0,134) \\
\end{array}$ & $\begin{array}{c}0,000 \\
(0,058) \\
\end{array}$ & $\begin{array}{c}0,039 \\
(0,072) \\
\end{array}$ \\
\hline${ }^{3}$ Taxa de câmbio nominal - Brasil & $\begin{array}{l}-0,321^{*} \\
(0,182)\end{array}$ & $\begin{array}{c}-0,091^{* *} \\
(0,047)\end{array}$ & $\begin{array}{l}-0,020 \\
(0,068) \\
\end{array}$ \\
\hline Tendência & $\begin{array}{c}-0,001 \\
(0,001)\end{array}$ & $\begin{array}{c}0,001^{* *} \\
(0,000)\end{array}$ & $\begin{array}{c}0,001^{* *} \\
(0,001)\end{array}$ \\
\hline Teste de Wu-Hausman & $\begin{array}{c}\mathrm{p} \text {-valor } \\
0,00\end{array}$ & - & - \\
\hline Teste de Pagan-Hall & $\begin{array}{c}\text { p-valor } \\
0,99\end{array}$ & - & - \\
\hline Teste de Cumby-Huizinga & $\begin{array}{c}\text { p-valor } \\
0,12\end{array}$ & - & - \\
\hline Teste de Sargan & $\begin{array}{c}\text { p-valor } \\
0,85\end{array}$ & - & - \\
\hline Teste LM de Breusch-Pagan & - & - & $\begin{array}{c}\mathrm{p} \text {-valor } \\
0,00\end{array}$ \\
\hline Teste de Hansen-Sargan & - & - & $\begin{array}{c}\text { p-valor } \\
0,06\end{array}$ \\
\hline
\end{tabular}

***Significativo a $1 \% ; * *$ Significativo a $5 \% ;$ * Significativo a $10 \%$

Variável dependente da função: preço de exportação de leite em pó integral da Argentina para o Brasil.

1. Elasticidade da demanda residual e variável dependente defasada; 2. Deslocadores de custos do concorrente; 3 . Deslocadores de demanda - Brasil. Obs.: Os desvios padrão estão entre parênteses, e as variáveis, em logaritmos.

Fonte: Resultados de pesquisa.

Desta forma, pelo MQ3E, um aumento de $1 \%$ na quantidade exportada pela Argentina agora está relacionado a uma redução de $0,13 \%$ nos preços, o que demonstra uma capacidade de alteração dos preços por meio da quantidade, ou seja, há um significativo poder de mercado sobre as exportações de leite em pó integral para o Brasil. As demais variáveis mantiveram o padrão estimado no SUR, com exceção da taxa de câmbio nominal do Uruguai.
Em suma, no que tange as exportações de leite em pó integral, verifica-se que a Argentina se comporta como um oligopolista em uma estrutura de concorrência imperfeita, tendo capacidade de exercer poder de mercado nas exportações para o Brasil.

Os resultados da função de demanda residual das exportações argentinas de leite em pó desnatado para o Brasil estão presentes na Tabela 3. 
Tabela 3. Estimativas da função de demanda residual para as exportações argentinas de leite em pó desnatado entre janeiro de 2002 a julho de 2013

\begin{tabular}{|c|c|c|c|}
\hline Método & MQ2E & SUR & MQ3E \\
\hline $\mathrm{R}^{2}$ & 0,955 & 0,930 & 0,828 \\
\hline Constante & $\begin{array}{l}-8,319^{*} \\
-4,982 \\
\end{array}$ & $\begin{array}{l}-0,391 \\
(0,527) \\
\end{array}$ & $\begin{array}{l}-3,989 \\
-2,761 \\
\end{array}$ \\
\hline${ }^{1}$ Quantidade exportada - Argentina & $\begin{array}{l}0,327^{*} \\
(0,198) \\
\end{array}$ & $\begin{array}{c}-0,002 \\
(0,011) \\
\end{array}$ & $\begin{array}{c}0,155 \\
(0,109) \\
\end{array}$ \\
\hline 1Preço de exportação defasado - Argentina & $\begin{array}{c}0,891^{* * *} \\
(0,251)\end{array}$ & $\begin{array}{c}0,591^{* * *} \\
(0,064)\end{array}$ & $\begin{array}{c}0,743^{* * *} \\
(0,146)\end{array}$ \\
\hline${ }^{2}$ Taxa de câmbio nominal - Uruguai & $\begin{array}{l}1,159^{*} \\
(0,593) \\
\end{array}$ & $\begin{array}{c}0,220^{* * *} \\
(0,075) \\
\end{array}$ & $\begin{array}{c}0,654^{* *} \\
(0,330) \\
\end{array}$ \\
\hline${ }^{2}$ Preço do leite ao produtor - Uruguai & $\begin{array}{c}0,580^{* * *} \\
(0,221) \\
\end{array}$ & $\begin{array}{c}0,368^{* *} \\
(0,067) \\
\end{array}$ & $\begin{array}{c}0,469^{* * *} \\
(0,131)\end{array}$ \\
\hline 3Índice de comércio nos supermercados - Brasil & $\begin{array}{c}0,473 \\
(0,315) \\
\end{array}$ & $\begin{array}{c}0,184^{* *} \\
(0,093)\end{array}$ & $\begin{array}{l}0,286^{*} \\
(0,186) \\
\end{array}$ \\
\hline Tendência & $\begin{array}{l}-0,008^{*} \\
(0,004) \\
\end{array}$ & $\begin{array}{c}-0,002^{* *} \\
(0,001)\end{array}$ & $\begin{array}{l}-0,005 \\
(0,002) \\
\end{array}$ \\
\hline Teste de Wu-Hausman & $\begin{array}{c}\mathrm{p} \text {-valor } \\
0,00\end{array}$ & - & - \\
\hline Teste de Pagan-Hall & $\begin{array}{c}\mathrm{p} \text {-valor } \\
0,99 \\
\end{array}$ & - & - \\
\hline Teste de Cumby-Huizinga & $\begin{array}{c}\text { p-valor } \\
0,07\end{array}$ & - & - \\
\hline Teste de Sargan & $\begin{array}{c}\text { p-valor } \\
0,95\end{array}$ & - & - \\
\hline Teste LM de Breusch-Pagan & - & - & $\begin{array}{c}\mathrm{p} \text {-valor } \\
0,07\end{array}$ \\
\hline Teste de Hansen-Sargan & - & - & $\begin{array}{c}\text { p-valor } \\
0,25\end{array}$ \\
\hline
\end{tabular}

*** Significativo a $1 \%$; **Significativo a $5 \%$; ${ }^{*}$ Significativo a $10 \%$

Variável dependente da função: preço de exportação de leite em pó desnatado da Argentina para o Brasil.

1. Elasticidade da demanda residual e variável dependente defasada; 2. Deslocadores de custos do concorrente; 3 . Deslocadores de demanda - Brasil. Obs.: Os desvios padrão estão entre parênteses, e as variáveis, em logaritmos.

Fonte: Resultados de pesquisa.

Os instrumentos utilizados na estimação por MQ2E são: taxa de câmbio nominal da Argentina atual e defasado um período e o preço de exportação do Uruguai atual e defasado um período. O teste de Wu-Hausman rejeita a hipótese nula de que a quantidade exportada é exógena a $1 \%$ de significância, indicando a necessidade de utilizar métodos que tratem da endogeneidade dos regressores. O teste de Pagan-Hall, por sua vez, não rejeita a hipótese nula de homocedasticidade dos erros da função, ao passo que o teste de Cumby-Huizinga não rejeita a hipótese de não haver autocorrelação entre os resíduos. Por fim, o teste de Sargan não rejeita a hipótese nula de que os instrumentos utilizados são válidos.
As estimativas pelo SUR não apresentaram grandes alterações com relação ao MQ2E. Por fim, a estimação por MQ3E apresenta um $R^{2}$ de 0,82, o teste de Hansen-Sargan não rejeita a hipótese de validade dos instrumentos e o teste LM de Breusch-Pagan rejeita a hipótese nula de que não há correlação contemporânea entre os erros das equações a $10 \%$ de significância, indicando que o MQ3E é o método mais adequado. Os resultados demonstram que o coeficiente da elasticidade da demanda residual não é estatisticamente significativo, além de não apresentar o sinal esperado. Isto demonstra que, no que tange as exportações de leite em pó desnatado para o Brasil, as firmas argentinas não têm capacidade de influenciar os 
preços, atuando como em um mercado em concorrência perfeita. Os coeficientes das demais variáveis não demonstraram maiores alterações com relação às estimativas anteriores.

\subsubsection{Uruguai}

Na Tabela 4 estão presentes as estimativas da função de demanda residual para as exportações de leite em pó integral das firmas uruguaias para o Brasil.

Para a estimativa da função de demanda residual por MQ2E foram utilizados os seguintes instrumentos com o intuito de tratar a endogeneidade da quantidade com relação ao preço: câmbio nominal do Uruguai atual e defasado um período, IPP - Gado e Leite da Argentina defasado um período e o índice de comércio nos supermercados brasileiro. Novamente, o teste de Wu-Hausman rejeita a hipótese de que a quantidade exportada seja exógena e, portanto, é justificada a utilização de métodos que tratem da endogeneidade. Por sua vez, o teste de Sargan não rejeita a hipótese de que os instrumentos utilizados são válidos, ao passo que os testes de Pagan-Hall e Cumby-Huizinga não rejeitam as hipóteses de não haver heterocedasticidade e autocorrelação, respectivamente.

Os resultados da função de demanda residual pelo método SUR não apresentaram grandes divergências do método anterior. Já o modelo estimado por MQ3E registra uma importante alteração se comparado às estimativas anteriores. A elasticidade da demanda residual mostra-se significativa a $1 \%$ de significância e com o sinal negativo esperado, indicando que uma elevação de $1 \%$

Tabela 4. Estimativas da função de demanda residual para as exportações uruguaias de leite em pó integral entre janeiro de 2002 a julho de 2013

\begin{tabular}{|c|c|c|c|}
\hline Método & MQ2E & SUR & MQ3E \\
\hline $\mathrm{R}^{2}$ & 0,959 & 0,866 & 0,846 \\
\hline Constante & $\begin{array}{l}-1,054^{*} \\
(0,543)\end{array}$ & $\begin{array}{c}0,814^{* * *} \\
(0,290)\end{array}$ & $\begin{array}{c}-0,829^{* * *} \\
(0,314)\end{array}$ \\
\hline${ }^{1}$ Quantidade exportada - Uruguai & $\begin{array}{l}-0,039 \\
(0,028) \\
\end{array}$ & $\begin{array}{c}-0,003 \\
(0,002) \\
\end{array}$ & $\begin{array}{c}-0,014^{* * *} \\
(0,004)\end{array}$ \\
\hline${ }^{1}$ Preço de exportação defasado - Uruguai & $\begin{array}{c}0,566^{* * *} \\
(0,157) \\
\end{array}$ & $\begin{array}{c}0,711^{* * *} \\
(0,053)\end{array}$ & $\begin{array}{c}0,691^{* * *} \\
(0,060)\end{array}$ \\
\hline 2IPP Gado e Leite - Argentina & $\begin{array}{l}0,174^{*} \\
(0,101)\end{array}$ & $\begin{array}{c}0,179^{* * *} \\
(0,061)\end{array}$ & $\begin{array}{c}0,159^{* *} \\
(0,066)\end{array}$ \\
\hline 3Índice de comércio nos supermercados - Brasil & $\begin{array}{c}0,208 \\
(0,246)\end{array}$ & $\begin{array}{c}0,017 \\
(0,109) \\
\end{array}$ & $\begin{array}{c}0,081 \\
(0,119) \\
\end{array}$ \\
\hline Teste de Wu-Hausman & $\begin{array}{c}\text { p-valor } \\
0,03\end{array}$ & - & - \\
\hline Teste de Pagan-Hall & $\begin{array}{c}\mathrm{p} \text {-valor } \\
0,35\end{array}$ & - & - \\
\hline Teste de Cumby-Huizinga & $\begin{array}{c}\text { p-valor } \\
0,30\end{array}$ & - & - \\
\hline Teste de Sargan & $\begin{array}{c}\text { p-valor } \\
0,35\end{array}$ & - & - \\
\hline Teste LM de Breusch-Pagan & - & - & $\begin{array}{c}\mathrm{p} \text {-valor } \\
0,00\end{array}$ \\
\hline Teste de Hansen-Sargan & - & - & $\begin{array}{c}\text { p-valor } \\
0,06\end{array}$ \\
\hline
\end{tabular}

***Significativo a $1 \%$; **Significativo a $5 \%$; *Significativo a $10 \%$

Variável dependente da função: preço de exportação de leite em pó integral do Uruguai para o Brasil.

1. Elasticidade da demanda residual e variável dependente defasada; 2. Deslocadores de custos do concorrente; 3 . Deslocadores de demanda - Brasil. Obs.: Os desvios padrões estão entre parênteses, e as variáveis, em logaritmos.

Fonte: Resultados de pesquisa. 
na quantidade exportada pelas firmas do Uruguai está relacionada a um decréscimo de $0,014 \%$ nos preços. Isto demonstra que as firmas uruguaias têm a capacidade de alterar os preços de exportação conforme variações na quantidade exportada pelo método analisado, o que indica a existência de poder de mercado. O teste de Hansen-Sargan não rejeita a hipótese de que os instrumentos sejam válidos a 5\% de significância, e o teste de ML de Breusch-Pagan rejeita a hipótese nula de que não há correlação contemporânea entre os erros das equações a 1\% de significância. Assim, conclui-se que o Uruguai exerce um poder de mercado estatisticamente significativo com relação às exportações de leite em pó integral para o Brasil, atuando, desta forma, como um agente em uma estrutura oligopolista de concorrência imperfeita.

As últimas estimativas são referentes à função de demanda residual das exportações uruguaias de leite em pó desnatado para o Brasil. Os resultados das estimações por MQ2E, SUR e MQ3E, bem como os testes necessários, estão presentes na Tabela 5.

Nas estimativas pelo MQ2E, os testes de Cumby-Huizinga e Pagan-Hall não rejeitam as respectivas hipóteses nulas de ausência de autocorrelação e heterocedasticidade a 5\% de significância estatística, ao passo que o teste de Sargan valida a utilização dos seguintes instrumentos: taxa de câmbio nominal do Uruguai atual e defasada, taxa de câmbio nominal da Argentina, taxa de câmbio nominal do Brasil e o preço do leite do produtor no Uruguai. O $\mathrm{R}^{2}$ das estimativas é de 0,93 e o teste de Wu-Hausman indica a necessidade de utilizar métodos que levem em consideração a endogeneidade na regressão.

As estimativas pelo SUR também apresentaram um bom ajuste de $\mathrm{R}^{2}=0,86$,

Tabela 5. Estimativas da função de demanda residual para as exportações uruguaias de leite em pó desnatado entre janeiro de 2002 a julho de 2013

\begin{tabular}{|c|c|c|c|}
\hline Método & MQ2E & SUR & MQ3E \\
\hline $\mathrm{R}^{2}$ & 0,934 & 0,863 & 0.67 \\
\hline Constante & $\begin{array}{c}-0.18 \\
-0.773 \\
\end{array}$ & $\begin{array}{l}-0.267 \\
-0.389 \\
\end{array}$ & $\begin{array}{l}-0.187 \\
-0.607 \\
\end{array}$ \\
\hline${ }^{1}$ Quantidade exportada - Uruguai & $\begin{array}{c}-0,053^{* * *} \\
(0,020) \\
\end{array}$ & $\begin{array}{c}0,005^{* *} \\
(0,003)\end{array}$ & $\begin{array}{c}-0,035^{* * *} \\
(0,012)\end{array}$ \\
\hline${ }^{1}$ Preço de exportação defasado - Uruguai & $\begin{array}{c}0,727^{* * *} \\
(0,107) \\
\end{array}$ & $\begin{array}{c}0,902^{* * *} \\
(0,044)\end{array}$ & $\begin{array}{c}0,787^{* * *} \\
(0,077)\end{array}$ \\
\hline${ }^{2}$ Taxa de câmbio nominal - Argentina & $\begin{array}{l}0,530^{*} \\
(0,293)\end{array}$ & $\begin{array}{c}-0,026 \\
(0,114) \\
\end{array}$ & $\begin{array}{l}0,357^{*} \\
(0,206)\end{array}$ \\
\hline 3Índice de comércio nos supermercados - Brasil & $\begin{array}{c}0,085 \\
(0,233) \\
\end{array}$ & $\begin{array}{c}0,078 \\
(0,117)\end{array}$ & $\begin{array}{c}0,078 \\
(0,183)\end{array}$ \\
\hline Teste de Wu-Hausman & $\begin{array}{c}\text { p-valor } \\
0,00\end{array}$ & - & - \\
\hline Teste de Pagan-Hall & $\begin{array}{c}\text { p-valor } \\
0,30\end{array}$ & - & - \\
\hline Teste de Cumby-Huizinga & $\begin{array}{c}\text { p-valor } \\
0,07\end{array}$ & - & - \\
\hline Teste de Sargan & $\begin{array}{c}\text { p-valor } \\
0,40\end{array}$ & - & - \\
\hline Teste LM de Breusch-Pagan & - & - & $\begin{array}{c}\text { p-valor } \\
0,07\end{array}$ \\
\hline Teste de Hansen-Sargan & - & - & $\begin{array}{c}\mathrm{p} \text {-valor } \\
0,25\end{array}$ \\
\hline
\end{tabular}

*** Significativo a $1 \%$; ** Significativo a $5 \% ;$ * Significativo a $10 \%$

Variável dependente da função: preço de exportação de leite em pó desnatado do Uruguai para o Brasil

1. Elasticidade da demanda residual e variável dependente defasada; 2. Deslocadores de custos do concorrente; 3 . Deslocadores de demanda - Brasil. Obs.: Os desvios padrões estão entre parênteses, e as variáveis, em logaritmos.

Fonte: Resultados de pesquisa. 
todavia, a elasticidade da demanda residual tem o sinal positivo, o que não é coerente com a teoria. Finalmente, a elasticidade da demanda residual estimada pelo MQ3E apresenta-se significativa e com o sinal negativo esperado. $\mathrm{O}$ aumento de $1 \%$ na quantidade exportada para o Brasil está associado ao decréscimo de 0,03\% nos preços de exportação. O teste de HansenSargan valida os instrumentos nas estimativas por MQ3E, e o teste ML de Breusch-Pagan rejeita a hipótese nula de que não há correlação contemporânea entre os erros das equações a 10\% de significância. Conclui-se, então, que há exercício de poder de mercado nas exportações de leite em pó desnatado do Uruguai para o Brasil. Desta forma, o Uruguai também atua como um oligopolista neste mercado, assim como no caso do leite em pó integral.

\subsection{Discussões}

Com base nos resultados encontrados, dois pontos merecem atenção. $\mathrm{O}$ primeiro refere-se ao consumo de leite e derivados no Brasil. Mesmo com uma grande oferta de leite e derivados, a demanda brasileira por lácteos tem-se elevado recentemente, e este é um fator que limita as exportações e incentiva as importações do país. Carvalho (2010) demonstra que, nos primeiros anos do século XXI, o consumo de derivados lácteos no Brasil cresceu de forma significativa principalmente pelas seguintes razões: aumento na renda média da população, novos hábitos de consumo, produtos mais atrativos e práticos que se adaptam às necessidades do consumidor, entre outros. Além disto, o Brasil registrou um crescimento representativo da classe média com a inserção de famílias que antes seriam consideradas de baixa renda, graças ao baixo índice de desemprego, aumento do salário real, políticas de distribuição de renda, entre outros. Assim, pelo fato de a produção de leite em pó ser alta e as exportações baixas, verifica-se que as importações funcionam como um meio de suprir a demanda existente no país. Dada a dependência do Brasil pela importação destes produtos, é natural que as firmas dos países exportadores tenham poder de mercado e consigam vender os produtos por preços favoráveis, isto é, acima dos custos de produção, tal como encontrado nas estimativas anteriores. Assim como exposto na introdução, o poder de mercado encontrado ainda é favorecido pela regionalização do consumo e pela concentração das importações em apenas dois países.

O segundo ponto é referente à capacidade de o Brasil ter poder de mercado nas importações. Foi salientado que o Brasil é um importante destino das exportações de leite em pó integral e desnatado da Argentina e Uruguai, todavia, alguns fatores levam a crer que o país não possui poder de oligopsônio. Em primeiro lugar, o leite em pó é um produto essencial, que apresenta baixa elasticidade preço da demanda. No modelo teórico de Cournot, tal como apresentado em Martin (2010), o poder de mercado do ofertante tem uma relação inversa com a elasticidade preço da demanda, isto é, quanto mais inelástica a demanda pelo produto, maior a capacidade do ofertante em elevar os preços. Desta forma, o natural é que Argentina e Uruguai tenham capacidade de barganha na realização dos contratos, cabendo ao Brasil apenas a aceitação ou não dos preços estabelecidos. Em segundo lugar, o Brasil é altamente dependente do leite em pó exportado por Argentina e Uruguai, porém, ambos exportam para outros destinos também relevantes. Venezuela, Cuba e países africanos são países que importam quantidades vultosas de leite em pó integral e desnatado de ambos os países. O grau de concentração das importações brasileiras é substancialmente maior que o grau de concentração das exportações de Argentina e Uruguai, o que favorece o exercício de poder de mercado por parte dos ofertantes e prejudica a capacidade de barganha do importador.

\section{Conclusões}

O presente trabalho teve como principal objetivo verificar o grau de concorrência nas exportações argentinas e uruguaias de leite em pó integral e desnatado para o Brasil, tendo como 
base a capacidade de as firmas exercerem poder de mercado. Utilizando o modelo de demanda residual estimado pelos métodos de MQ2E, SUR e MQ3E, com ênfase nos resultados apresentados pelo último, verificou-se que, com relação às exportações de leite em pó integral, tanto as firmas argentinas quanto as uruguaias têm a capacidade de exercer poder de mercado, e, por isto, ambos os países atuam como oligopolistas em uma estrutura de concorrência imperfeita neste mercado. A primeira hipótese do presente trabalho é, portanto, não rejeitada. Por outro lado, com relação às exportações de leite em pó desnatado, apenas as firmas uruguaias exercem significativo poder de mercado, atuando como oligopolista. As firmas argentinas atuam como agentes em um mercado de concorrência perfeita, fazendo com que a segunda hipótese seja rejeitada.

Com base nos resultados, considera-se que deveria haver maior preocupação por parte do Brasil em aumentar a concorrência nas importações destes derivados, já que com isto os preços tenderiam a ser menores. Uma das alternativas seria incluir outros países nos acordos comerciais, elevando a concorrência pelo número de participantes do mercado. Todavia, o comércio internacional de lácteos é bastante restrito, e poucos países são capazes de exportar quantidades significativas. Em adição, o Brasil faz parte do Mercosul, e com isto é natural que importe mais de Argentina e Uruguai, já que Paraguai e Venezuela não são exportadores tradicionais de leite em pó. Assim, uma alternativa viável seria haver maior número de acordos bilaterais com países fora do Mercosul. Outra sugestão viável seria o Brasil incentivar a produção nacional de leite em pó integral e desnatado. Maior concorrência também seria gerada desta forma, com possível redução dos preços tanto da produção interna quanto dos produtos advindos de outros países. Neste sentido, deveria haver maior preocupação por parte da iniciativa pública e privada em pesquisa e desenvolvimento na produção primária de leite, desoneração tributária na aquisição do maquinário e de mão de obra, maior oferta de crédito para produtores primários e para as indústrias que produzem bens mais elaborados, entre outras políticas que poderiam incentivar a produção nacional de forma competitiva.

Como limitação, o modelo de demanda residual utilizado no presente trabalho é estimado com dados agregados, em que todas as firmas são representadas por dados referentes aos países. A pressuposição não é de simetria das firmas, mas sim que os dados refletem as médias ponderadas das mesmas. Como sugestão para estudos futuros, seria interessante tentar obter dados desagregados para estimação e verificar se os resultados obtidos são condizentes com o presente estudo.

\section{Referências}

AGUIAR, D. R. D. e FIGUEIREDO, A. M. Poder de mercado no varejo alimentar: uma análise usando os preços do estado de São Paulo. Revista de Economia e Sociologia Rural, v. 49, n. 4, p. 967-990, 2011.

ALICEWEB MERCOSUL. SECEX/MDIC, Brasília, DF, 2013. Disponível em: <www.alicewebmercosul.mdic. gov.br>. Acesso em: 16 dez. 2013.

BAKER, J. B. e BRESNAHAN, T. M. Estimating the Residual Demand Curve Facing a Single Firm. International Journal of Industrial Organization, v. 6, p. 283-300, 1988.

BRAGANÇA, G. G. F. Poder de mercado via demanda residual: o café brasileiro nos EUA. In: BRAGA, M. J.; AGUIAR, D. R. D.; TEIXEIRA, E. C. T. Defesa $d a$ concorrência e poder de mercado no agronegócio. Viçosa: UFV, 2005.

BRESNAHAN, T. F. Empirical Studies of Industries with Market Power. In: SCHMALENSEE, R.; WILLIG, R. D. (Org.). Handbook of industrial organization, Vol. 2. Amsterdam Netherlands: Elsevier, 1989, p. 1011-1157.

CAKIR, M. e BALAGTAS, J. V. Estimating Market Power of U.S. Dairy Cooperatives in the Fluid Milk Market. American Journal of Agricultural Economics, v. 94, n. 3, p. 647-658, 2012.

CARVALHO, G. R. A indústria de laticínios no Brasil: passado, presente e futuro. Circular técnica 102. Embrapa Gado de Leite, Juiz de Fora. 2010. Disponível em: <http://www.infoteca.cnptia.embrapa.br/bitstream/ doc/870411/1/CT102.pdf> . Acesso em: 20 dez. 2013.

CORONEL, A. C. et al. Poder de mercado das exportações de farelo de soja: uma análise via demanda 
residual. Revista de Economia Contemporânea, v. 14, n. 3, p. 587-612, 2010.

CUMBY, R. E. e HUIZINGA, J. Testing the autocorrelation structure of disturbances in ordinary least squares and instrumental variables regressions. Econometrica, v. 60, n. 1, p. 185-195, 1992.

FAO - Food and Agriculture Organization. Rome, 2014. Disponível em: < http://faostat.fao.org/>. Acesso em: 20 dez. 2013.

FAPRI - Food and Agriculture Policy Research Institute. 2014. Disponível em: < http://www.fapri.iastate.edu/>. Acesso em: 20 dez. 2013.

GOLDBERG, P. K. e KNETTER, M. M. Measuring the intensity of competition in exports markets. Journal of International Economics, v. 47, p. 27-60, 1999.

IBGE - Instituto Brasileiro de Geografia e Estatística, 2013. Disponível em: <www.ibge.gov.br>. Acesso em: 14 dez. 2013.

INALE. Instituto Nacional de la Leche. Uruguai. 2014. Disponível em: <www.inale.org>. Acesso em: $15 \mathrm{dez}$. 2013.

Situación y Perspectivasde la Lechería Uruguaya, Enero, Diciembre 2012. Informes Inale. Disponível em: <http://www.inale.org/innovaportal/ file/2314/1/inale_situacion_y_perspectivas_de_la_ lecheria_uruguaya_ene-dic_2012.pdf $>$. Acesso em: 10 jan. 2014.

INDEC. Instituto Nacional de Estatisticas y Censos de la Republica Argentina. Disponível em: < http://www. indec.mecon.ar/>. Acesso em: 10 dez. 2013.

IPEADATA. Disponível em: <http://www.ipeadata. gov.br>. Acesso em: 3 dez. 2013.
LEITE, J. L. B. e CARVALHO. G. R. O comércio mundial de lácteos e a participação brasileira. In: LEITE, J. L. B. et al. (Ed.). Comércio Internacional de Lácteos. 2. ed. Juiz de Fora: Embrapa Gado de Leite, 2009, p. 11-32.

LERNER, A. The concept of monopoly and the measurement of monopoly power. Review of Economic Studies, v. 1, p. 57-175, 1934.

MARTIN, S. Industrial Organization in Context. Oxford: Oxford University Press, 2010.

MAS-COLELL, A., WHINSTON, M. e GREEN, J. Microeconomic theory. Oxford University Press, 1995.

PAGAN, A. R. e HALL, D. Diagnostic Tests as Residual Analysis. Econometric Reviews, v. 2, n. 2, p. 159-218, 1983.

PROFETA, G. A. e BRAGA, M. J. Poder de mercado na indústria brasileira de fertilizantes NPK (04-14-08), no período de 1993-2006. Revista de Economia e Sociologia Rural, v. 49, n. 4, p. 837-855, 2011.

SHEHATA, E. A. E. LMCOVREG3: Stata Module to Compute Breusch-Pagan Lagrange Multiplier Diagonal Covariance Matrix Test after (3SLS-SURE) Regressions. 2012.

SISTEMA AliceWeb, SECEX/MDIC, Brasília, DF, 2013. Disponível em: <http://aliceweb.desenvolvimento. gov.br>. Acesso em: 20 nov. 2013.

STEEN, F. e SALVANES, K. G. Testing for market power using a dynamic oligopoly model. International Journal of Industrial Organization, v. 17, n. 2, p. 147-177, 1999.

UNCOMTRADE. United Nations Commodity Trade System. 2013. Disponível em: <http://comtrade. un.org >. Acesso em: 25 nov. 2013. 
